\section{BRANKO PEJOVIĆ 1 , DRAGAN STEVIĆ ${ }^{*}$, VLADAN MIĆIĆ}

${ }^{1}$ Faculty of technical science, Kosovska Mitrovica, Serbia

${ }^{2}$ Faculty of Technology, Zvornik, Republic of Srpska, B\&H
Scientific paper

UDC:65.012.261.001.26

doi:10.5937/ZasMat1503354P

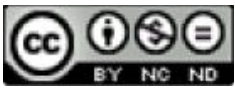

Zastita Materijala 56 (3)

$354-366$ (2015)

\title{
Optimization of dimension of weldment locus by method of geometric programming
}

\begin{abstract}
This paper, on the example of a typical loaded welded assembly, made optimization of its dimensions in terms of the cost of welding. In such an elaboration the mathematical optimization model with limitation functions has also been presented and it should be taken into account in the process of designing by the technologist and designer.

To solve the presented problem the method of geometric programming was proposed that has in detail been elaborated in the paper in the form of an algorithm suitable for the application. In this way the optimization or primary task was reduced to a dual task through a proper function, which is much easier to solve.

The method has been illustrated on a practical computational example with a different number of limitation functions. It is shown that in case of a lower degree of complexity the solution can be reached by maximizing the corresponding dual function by means of mathematical analysis. In case of a higher degree of complexity, it is necessary to use some of the methods of non-linear programming. In this case the solution of the problem is simplified due to the minimization of a linear equation.
\end{abstract}

Keywords: Alphabetic loaded welded structures, the mathematical model of optimization, the cost function, feature limitations, geometric programming, positive polynomials, dual function.

\section{MATHEMATICAL MODEL OF OPTIMIZATION}

Mathematical basis of techno-economic optimization of the objects is the mathematic model of optimization. Model of optimization according to figure 1 consists of the components:

- State functions $F_{s i}(\mathrm{i}=1,2,3 \ldots)$,

- Limit function (function boundary conditions) $F_{g i}$ $(i=1,2,3 \ldots)$,

- Criteria optimization and

- The objective function $F_{c i}(i=1,2,3 \ldots)$.

The first two components, ie. state functions or state equation and the limit function object of the mathematical model of the object is defined. Real objects imply a wide range of phenomena, processes and systems as very frequent objects of modelling in mechanical engineering and machining as technological processes [1,2].

${ }^{*}$ Corresponding author: Dragan Stević e-mail: dragancestevic@gmail.com

Paper received: 23. 03.2015.

Paper accepted: 11.05.2015.

Paper is available on the website: www.idk.org.rs/casopis

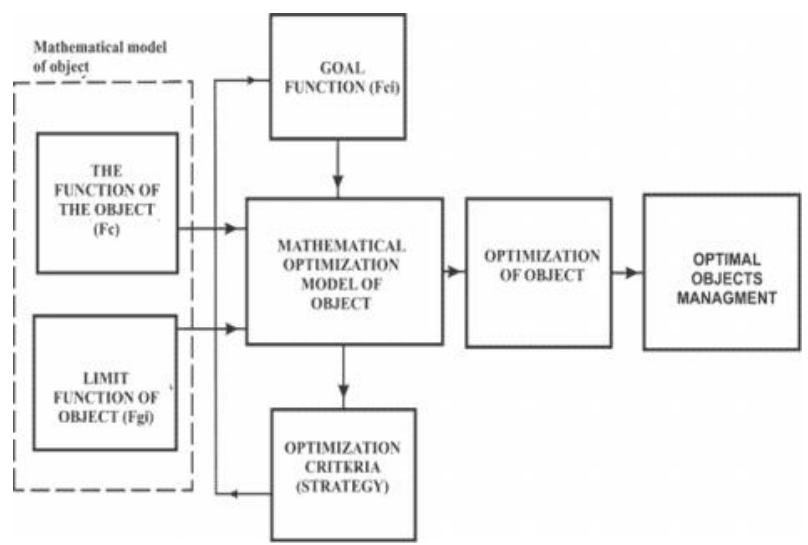

Figure 1 - The structure of the mathematical model of optimization object

It should be noted that the mathematical model, as opposed to the physical retains the physical nature of the originals (real property), showing the mathematical abstraction. This abstract form expresses the essential physical, geometrical, technological, economic or any other features of the real object, $[3,4]$.

The mathematical model of a machining process can be generally shown schematically by Figure 2. 


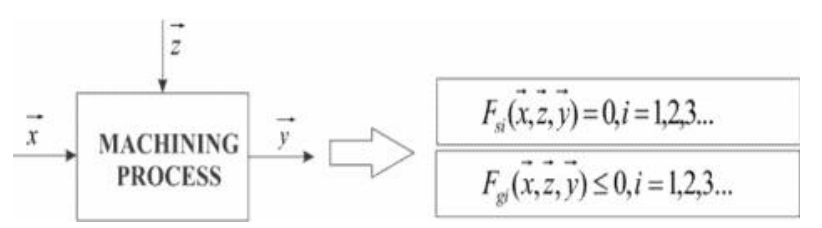

Figure 2 - The mathematical model of the machining process

In this, it is necessary to analyze the inputs and outputs of "natural" process and all sets of inputoutput variables $x_{i}, y_{i}, z_{i} \mathrm{i}=1,2,3 \ldots$ for each decomposed "elementary" process. This is a "natural" process that constitutes the core of the machining process and should describe the mathematical model of the process [5-7].

After analyzing the existing restrictions one accesses the mathematical description of the object in the mathematical language as a specific set of functions and equations. Thus the main features of the mathematical model are a function of the state of $F_{s i}$ and function limitations $F_{g i}$.

Considering the scheme in Figure 2, we can set up a mathematical model of any machining process in production engineering (with and without removing the chip, and beyond), through the functions of the process:

$$
F_{s i}=(\vec{x}, \vec{y}, \vec{z})=0, i=1,2,3 \ldots,
$$

and the limit function:

$$
F_{g i}=(\vec{x}, \vec{y}, \vec{z}) \leq 0 \quad i=1,2,3 \ldots,
$$

The mathematical models (1) and (2) are essentially physical, geometrical, technological and economic dependent qualimetric within the machining process and to the admissible domain $D$ resizing.

The system $(1,2)$ vectors $\vec{x}, \vec{y}$, and $\vec{z}$ denote a set of variables input- output variables of the process. Vector characteristics of the process states or controlled size

$$
\vec{y}=\left(y_{1}, y_{2}, y_{3}, \ldots y_{n}\right) \text {, }
$$

describe the state and behavior of the machining process and the system was created as a consequence of inputs $\vec{x}$, and $\vec{z}$. Input parameters, which are numerous, are divided into controlled $(\vec{x})$ and uncontrolled $(\vec{z})$ size of the process. The vector $\vec{x}$, includes all inputs to the process whose value can be measured numerically. The vector $\vec{x}=\left(x_{1}, x_{2}, x_{3}, \ldots x_{p}\right)$, can be broken down into a group optimal or control the size and groups that are constant in the course of the process. The first group can be changed in the process in order to achieve the desired state of the process $(\vec{y})$ and optimum objective function $\left(F_{c}\right)$.
Vector uncontrolled size $\vec{z}=\left(z_{1}, z_{2}, z_{3}, \ldots\right)$ contains one input parameters whose values can not be measured, as well as those that can be measured, but whose impact on the negligibly small. Vector causes adverse conditions and adverse changes in the flow characteristics of the process $(\vec{y})$ or the objective function $\left(F_{c}\right)$.

For the case of deterministic processes impact of uncontrolled factors $\vec{z}$ is not large, there is a correlation between the characteristics of states $\vec{y}$

and inputs $\vec{x}$. For this model, the size $\vec{z}$ will not be contained in the relations (1) and (2), so that it is obtained:

$$
\begin{aligned}
& F_{s i}=(\vec{x}, \vec{y})=0 i=1,2,3 \ldots, \\
& F_{g i}=(\vec{x}, \vec{y}) \leq 0 i=1,2,3 \ldots,
\end{aligned}
$$

or in the form of an explicit,

$$
\vec{y}=F(\vec{x}),
$$

Components of the state functions and function limitations, as it is said, is defined as the mathematical model while the optimization criteria as the third component, together with the first two, sets the framework mathematical model of optimization. On the basis of these three components, there is a specific form of the objective function (optimization functions):

$$
F_{c}=F_{c}(\vec{x}, \vec{y}, \vec{z}),
$$

Function (6) is a mathematical description of the optimal control process, the identified optimization criteria.

In theory, techno-economic optimization can be extracted more optimization criteria or objective functions $\left(F_{c}\right)$ according to which the optimized processes, [8,9,2,10]:Cost $\left(T_{i}\right)$, Build time $\left(T_{u i}\right)$, Economy $\left(E_{i}\right)$, Productivity $\left(P_{i}\right)$, Profitability $\left(R_{i}\right)$, Quality $\left(K_{i}\right)$.

Bringing to criteria optimization

$$
F_{c i}=\left(T_{i}, t_{u i}, E_{i}, P_{i}, R_{i}, K_{i} \ldots\right) \text {, }
$$

which shows key production effects, and also functions $F_{g i}$ constraints, which limit the allowed domain $D$ changes of input, into a functional relationship with a set of input and the other mentioned factors, according to (6) and (2), is obtained by the mathematical model of optimization deterministic process:

$$
\begin{aligned}
& F_{c}=F_{c}\left(x_{1}, x_{2}, x_{3}, \ldots x_{p}\right), \\
& x \in D \quad D\left\{\begin{array}{l}
x_{i}=c_{i} \\
a_{r} \leq x_{i} \leq b_{r} \\
F_{g j}\left(x_{1}, x_{2}, x_{3}, \ldots x_{D}\right) \leq 0
\end{array}\right.
\end{aligned}
$$

Techno-economic optimization is reduced to a mathematical point of view, the definition of 
extremal (optimal) objective function (8) and of corresponding of managed size and characteristics of the state of the process that provides the optimum, as shown in Figure 3, $[1,3,11]$.
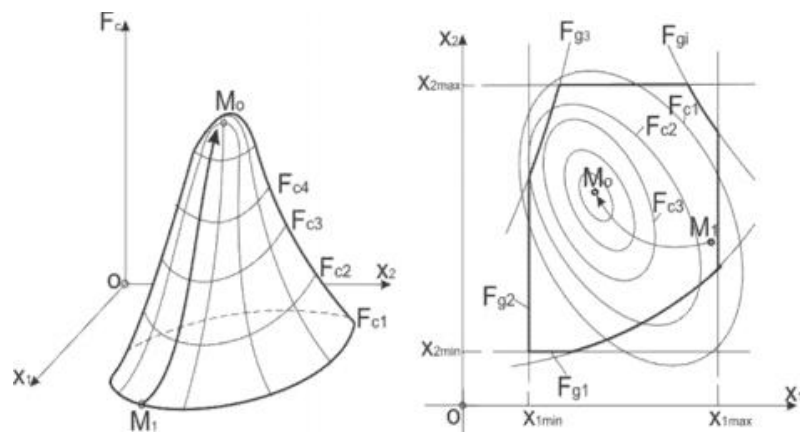

Figure 3 - Diagram of surface features to optimize the optimal range

The optimal level or solution $\vec{x}_{0}=\left(x_{10}, x_{20}, x_{30}, \ldots x_{k 0}\right)$ of the objective function (8) is called a local extremum, and point $M_{0}$ (defined vector $\vec{x}_{0}$ ) is called a point of local extremum. Function $F_{c}$ may have several local extremes.

To form the mathematical model of optimization according to (8), in addition to mathematical expressions objective function $F_{c}$, it is necessary to set up a mathematical expression of all necessary functions restrictions $F_{g i}, i=1,2,3, \ldots$ This way, defines and limits of permissible or the optimal area, region or domain $D$. All these constraints can be expressed in the form of equations and inequalities containing, among others, and given the size of sets of input values $x_{i},[8,12]$

According exposed, it can be concluded that the mathematical model of optimization, no matter what the subject is the word (process, system, structure, management, etc.) must always contain, as in the case of machining process, four basic components: Function of the facility, Limit function, The criteria optimization, Function of optimization or objective function.

Based on these components, forming the final shape of the model optimization of a given object that expresses the function optimization $F_{c}=F_{c}\left(x_{i}\right)$ and the permitted domain $D$ transformations of variables $x_{i}$.

\section{THE METHOD OF GEOMETRIC PROGRAMMING}

This method can solve those optimization tasks whose optimization functions are in the form of positive polynomials:

$$
F_{c}(x)=\sum_{j=1}^{k} B_{j} \sum_{i=1}^{k} x_{i}^{b_{i j}}
$$

where: $B_{j}$-positive coefficients (constants), bijexponents, random number, which may be positive, negative or zero value, $x_{i}$-independent variables (variables) that can only have positive values.

The algorithm of method, which will be summarized in the following, allows to determine the optimal solution $\vec{x}_{0}=\left(x_{10}, x_{20}, x_{30}, \ldots x_{k 0}\right)$ with the $F_{c \text { min, }}$ [13-16].

In many cases, the optimization of machining processes and technology in terms of cost, where the optimization function is expressed as a positive polynomial (9), it is possible to effective application of the method of geometric programming.

\subsection{The basic inequality methods}

In developing the algorithm method of geometric programming, starting from the mathematical inequality between geometric and arithmetic means of non-negative numbers. This inequality is the foundation of the method and two sizes as follows, $[16,12,17,3,4]$.

$$
\frac{1}{2}\left(Z_{1}+Z_{2}\right) \geq \sqrt{Z_{1} Z_{2}}
$$

This relation expresses the view that geometry can not be greater than arithmetic means.

Inequality (10), for $\mathrm{k}$ variables is:

$$
\sum_{j=1}^{r} q_{j} Z_{j}>\prod_{j=1}^{r} Z_{j} q_{j}
$$

and it is valid that the size $Z_{j}$ positive and positive size $q_{i}$ satisfy the condition of normality,

$$
\sum_{j=1}^{r} q_{j}=1
$$

From equation (11), we can write the basic equations of the method of geometric programming:

$$
\sum_{j=1}^{r} z_{j} \geq \sum_{j=1}^{r}\left(\frac{z_{j}}{q_{j}}\right)^{q_{j}},
$$

The previous equation is obtained when the inequality in replacing,

$$
z_{j}=q_{j} Z_{j},
$$

where in a $z_{j}>0$.

Inequality (14) has a fundamental meaning for the method of geometric programming because the application of this inequality to the function optimization (9) may change:

$$
z_{j}(x)=B_{j} \prod_{i=1}^{k} x_{i}^{b_{i j}}
$$

in equation (13), write the basic of mathematical method 


$$
\sum_{j=1}^{r} B_{j} \prod_{i=1}^{k} x_{i}^{b_{i j}} \geq \prod_{j=1}^{r}\left(\frac{B_{j}}{q_{j}}\right)^{q_{j}} \prod_{i=1}^{k} x_{i}^{L_{i}},
$$

where in,

$$
L_{i}=\sum_{j=1}^{r} q_{j} b_{i j},
$$

It was pointed out that inequality (16) is valid for any positive values of size $q_{i}$, which must satisfy the condition of normality (12). Proceeding from this, we can simplify the inequality (16) the choice of values for $q_{i}$ to obtain $L_{i}=0$ in equation (17), ie.

$$
L_{i}=\sum_{j=1}^{r} q_{j} b_{i j}=0 \quad i=\overline{1, k},
$$

Equation $(X)$ simplified the fundamental expression $(X)$, which now reads:

$$
\sum_{j=1}^{r} B_{j} \prod_{i=1}^{k} x_{i}^{b_{i j}} \geq \prod_{j=1}^{r}\left(\frac{B_{j}}{q_{j}}\right)^{q_{j}},
$$

This equation applies to the condition of normality:

$$
\sum_{j=1}^{r} q_{j}=1
$$

orthogonality, in accordance with equation (17), ie.

$$
\begin{aligned}
& L_{i}=0 \\
& \sum_{j=1}^{r} q_{j} b_{i j}=0 \quad i=\overline{1, k},
\end{aligned}
$$

and the condition of positivity:

$$
q_{j}>0 \quad i=\overline{1, r},
$$

Right side of the inequality (19) is a function of the size of $q_{j}(i=\overline{1, r})$, as can be seen, ie.

$$
Q(q)=\prod_{j=1}^{r}\left(\frac{B_{j}}{q_{j}}\right)^{q_{j}},
$$

and is called a dual function of a convex function (9), because the positive polynomial (9) is a convex function.

Left $F_{c}$ inequality (19), however, depends only on the independent variables $x_{j}(i=\overline{1, r})$.

The following conclusion is: at the basis of the fundamental inequality, a polynomial of positive $F_{c}$ $(X)$ cannot be, whatever kind of values are the variables $x_{j}(i=\overline{1, r})$,smaller than the dual function $Q(q),(X)$, and the primary model, i.e. minimization function $F_{c}$, down to the dual model, ie. the maximization of the dual function $Q(q)$. So there is a primary reformulation (base, starting) in finding the optimization dual task, since it can be shown
$[15,7,16]$ that is a maximum value of the dual function $Q(q)$ equal to the minimum value of the basic functions in the form of a positive $F_{c}$ polynomials, ie.

$$
\min F_{c}(x)=\max \sum_{j=1}^{r}\left(\frac{B_{j}}{q_{j}}\right)^{q_{j}},
$$

In these conditions must be met (20), (21) and (22) of the dual variable $\mathrm{Q}_{\mathrm{j}}(i=\overline{1, k})$. So optimization (primary) task,

$$
\begin{aligned}
& F_{c \min }=\min \sum_{j=1}^{r} B_{j} \prod_{i=1}^{k} x_{i}^{b_{i j}}=F_{c 0}, \\
& x_{i}>0 \\
& Q(q)_{\max }=\max \prod_{j=1}^{r}\left(\frac{B_{j}}{q_{j}}\right)^{q_{j}}=Q_{0}, \\
& \sum_{j=1}^{r} q_{j}=1 \sum_{j=1}^{r} q_{j} b_{i j}=0 \quad i=\overline{1, k} \\
& q_{j}>0 \quad i=\overline{1, r}
\end{aligned}
$$

which is much easier to solve in respect of the primary task (25), i.e. determination of $F_{c}$ min, $F_{c}$ optimization function.

\subsection{Algorithm of method}

At present, there are two possible cases as follows:

- The case without restrictions

- The case of the constraints

In case that there are no limitation equations (24) or system (25) is defined by the minimum value (optimum) function optimization $F_{c 0}(9)$ over the maximum $Q_{0}$, ie. determining the optimal level $F_{c 0}$ positive polynomial $F_{c}$ testifies to the determination of the maximum value $Q_{0}$ dual function $Q(q)$. It would be the first step of the method.

In the second step is calculated the optimal dual vector $\vec{q}_{0}=\left(q_{10}, q_{20}, q_{30}, \ldots q_{k 0}\right)$ system of equations:

$$
\sum_{j=1}^{r} q_{j}=1 \quad \sum_{j=1}^{r} q_{j} b_{i j}=0 \quad i=\overline{1, k},
$$

which represents the conditions of normality and orthogonality.

In the third step is determined the maximum value $Q_{0}$ dual function $Q(q)$, which is based on a known set $\vec{q}_{0}$ (determined in the second step), as calculated from the equation: 


$$
Q_{0}=\max \prod_{j=1}^{r}\left(\frac{B_{j}}{q_{j 0}}\right)^{q_{j 0}},
$$

The fourth step involves the determination of optimal primary vector (solution) $\vec{x}_{0}=\left(x_{10}, x_{20}, x_{30}, \ldots x_{k 0}\right)$.

The functions of the $F_{c}$, (9) found on the basis of the values $F_{c 0}=Q_{0}$ in the third step. Between $\vec{x}_{0}$ that minimizes the function $F_{c}=F_{0}$, the optimal dual vector $\vec{q}_{0}$ which satisfies the conditions of normality and orthogonality (26), the second step becomes as follows:

$$
Q_{0} q_{0}=B_{j} \prod_{i=1}^{k} x_{i 0} b_{i j} i=\overline{1, r},
$$

From equation (28), we obtain the required optimal level $\vec{x}_{0}$, where the size of $Q_{0}=F_{c 0}$ and $q_{j 0}$ $(i=\overline{1, r})$ are known, as well as some of the second or third step.

In case you are given the limitations in the form of the function:

$$
\begin{aligned}
& F_{g 1} \leq 1, F_{g 2} \leq 1, F_{g 3} \leq 1, \ldots, \\
& F_{g p} \leq 1
\end{aligned}
$$

then the primary task reads

$$
\begin{aligned}
& F_{c \min }=\min \sum_{j=1}^{r} F_{j} \prod_{i=1}^{k} x_{i}^{b_{i j}}, \\
& F_{g 1} \leq 1, F_{g 2} \leq 1, F_{g 3} \leq 1, \ldots, \\
& F_{g p} \leq 1 x_{1}>0, x_{2}>0, x_{3}>0, \ldots, \\
& x_{k}>0
\end{aligned}
$$

wherein the function restriction $F_{g t}(t=\overline{1, p})$ has the shape of a positive polynomials

$$
\begin{aligned}
& F_{g t}=\min \sum_{j \in J(t)} B_{j} \prod_{i=1}^{k} x_{i}^{b_{i j}}, \\
& t=1,2,3, \ldots, p
\end{aligned}
$$

Where in:

$J(0)\left(1, \ldots, m_{0}\right)$ - indexes of individual members function $\mathrm{F}_{\mathrm{c}}$

$J$ (1) $\left(m_{0}+1 \quad \ldots, m_{1}\right)$ - indexes of individual members function $f_{g 1}$

$J(2)\left(m_{1}+1, \ldots, m_{2}\right)$ - indexes of individual members function $\mathrm{F}_{\mathrm{g} 2 \ldots} \ldots$

$J(p)\left(m_{p-1}+1, \ldots, m_{p}=r\right)$ - indexes of individual members function $\mathrm{F}_{\mathrm{gp}}$,

Here, the functions $F_{c}$ and $F_{g p}$ are in the shape of a positive polynomial.
With corresponding dual task, in which the primary task is reduced, we can show and express the system:

$$
\begin{aligned}
& Q(q)_{\max }=\max \left[\prod_{j=1}^{r}\left(\frac{B_{j}}{q_{j}}\right)^{q_{j}}\right] \prod_{t=1}^{p} \lambda_{t}^{\lambda_{t}}, \\
& \lambda_{t}=\sum_{j \in J(t)} q_{j} \quad t=1,2,3, \ldots, p, \\
& \sum_{j=1}^{r} q_{j}=1 \sum_{j=1}^{r} q_{j} b_{i j}=0 \quad i=\overline{1, k}, \\
& q_{j}>0 \quad i=\overline{1, r},
\end{aligned}
$$

As we see from (32) see in equation (33) are entered all coefficients $B_{j}$ containing $F_{c}$ function and system function limitations $F_{g t}(t=\overline{1, p})$. Here, conditions (35) and (36) are conditions of normality, orthogonality and positivity, respectively.

The further course of the optimization algorithm given object is identical to the method of geometric programming algorithm without constraints. However, the equations (28) to determine the optimum number of the primary vector in this case is modified to read as follows:

$$
B_{j} \prod_{i=1}^{k} x_{i}^{b_{i j}}=\left\{\begin{array}{l}
Q_{0} q_{j 0} \text { za } j \in J(0) \\
\frac{q_{j 0}}{\lambda_{t 0}} \text { za } j \in J(t) \quad t=\overrightarrow{1, p}
\end{array}\right.
$$

wherein:

$$
\lambda_{t 0}=\sum_{j \in J(t)} q_{j 0}
$$

\section{CALCULATION EXAMPLES}

The general task of optimizing the mathematical model of the illustrated two examples of the structural unit is related to the optimization of dimensions of the welded assembly loaded in terms of the welding costs.

\subsection{A simple example}

In the first example, Figure 4 circuit consists of two elements: beams (girders) 1 with weld and hokder (reliance, where the beam is fixed to a rigid bracket welded weld I and II.

\section{a) Definition of fixed and variable size}

According to the exposed the next procedure must be defined first as well as unchangeable variable resolution image. Conditions of the problem are given constant (unchangeable) size: kinds of materials of manufacturers, the free length of the beam (units) $L$ and the maximum force $F$ on loaded beams. 
Other dimensions of the assembly are independent variables. These dimensions are:

$$
h=x_{1} l=x_{2} t=x_{3} b=x_{4} \text {, }
$$

The value of these dimensions should be so determined and optimized to achieve an optimal vector $\vec{x}_{0}=\left(x_{10}=h_{0}, x_{20}=I_{0}, x_{30}=t_{0}, x_{0}=b_{0}\right)$ of minimum cost of welding. $\mathrm{Fcmin}=\mathrm{Fco}=\operatorname{min~T}$.

b) Defining the mathematical form of function optimization

The cost function as a function of optimization can be written as, [18-22].

$$
T=T_{p}+T_{1}+T_{2},
$$

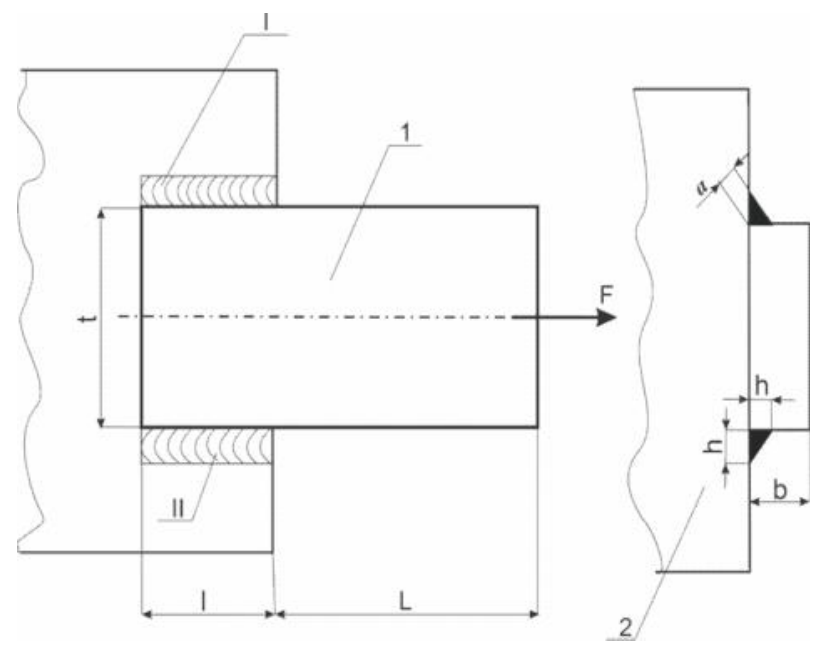

Figure 4 - Loaded weldments

These functions consist of three main components (partial charges): $T_{p}$ - the costs of preparation (preparatory operations), $T_{1}$-welding costs, $T_{2}$-the cost (price) of material.

Costs of preparation $T_{p}$ refer to all the necessary technological equipment to perform welding operations: welding tools, auxiliary equipment for setting beams on the truss in position, its tightness and more. These costs will be considered constant (do not depend on the variables $\left(x_{1}, x_{2}, x_{3}\right.$, and $\left.x_{4}\right)$.

Cost of welding operations $T_{1}$ can be determined if you know the elements of these costs:

$T_{11}$ - the cost of using welding expressed in monetary amount per unit of time, which includes the cost of amortization and loan repayment appliances, the cost of auxiliary equipment (depreciation) used in welding, the cost of human work (personal income from contributions and other),

$Q_{z}$ - The capacity ie. volume of weld (weld) per unit time and,

$V_{z}$ - volume of weldment, weld I and II, that the example given is calculated as:

$$
V=V_{z 1}+V_{z 2}=\frac{1}{2} h^{2} I+\frac{1}{2} h^{2} I=h^{2} I,
$$

as follows according to figure 4 .

On the basis of these elements can be written T1 costs:

$$
T_{1}=\frac{T_{11}}{Q_{z}} V_{z}=\frac{T_{11}}{Q_{z}} h^{2} l,
$$

The cost of materials will be:

$$
T_{2}=T_{3} V_{z}+T_{4} V_{G},
$$

Where in: $T_{3}$ - material price of weld, $T_{4}$ material price beam, $V_{g}$ - volume of the beam is calculated as:

$$
V_{G}=t \cdot b \cdot(b+l),
$$

replacing (41) and (44) to (43) will be:

$$
T_{2}=T_{3} \cdot h^{2} I+T_{4} \cdot t \cdot b \cdot(L+I),
$$

Costs by replacing (42) and (45) in (40) we obtain the desired shape optimization function (objective function):

$$
\begin{aligned}
& F_{c}=T=T_{p}+\frac{T_{11}}{Q_{z}} \cdot h^{2} I+T_{3} \cdot h^{2} I+ \\
& +T_{4} \cdot t \cdot b \cdot(L+I),
\end{aligned}
$$

respectively:

$$
T=T_{p}+\left(\frac{T_{11}}{Q_{z}}+T_{3}\right) \cdot h^{2} I+T_{4} \cdot t \cdot b \cdot(L+I),
$$

or by (39):

$$
T=T_{p}+\left(\frac{T_{11}}{Q_{z}}+T_{3}\right) \cdot x_{1}^{2} \cdot x_{2}+T_{4} \cdot x_{2} \cdot x_{3} \cdot x_{4}+
$$$$
+T_{4} \cdot L \cdot x_{3} \cdot x_{4},
$$

the present values of the coefficients $T_{11}, Q_{z}, T_{3}, T_{4}$ and $L$-known of the given task (objective optimization).

c) Defining and setting up a system function limitations

1. Restrictions on the power of the shear in the weld [21-23].

The actual shear stress in the weld will be, in view of the computational of weld $a=\frac{h \sqrt{2}}{2}$, Figure 4.

$$
\begin{aligned}
& \tau=\tau\left(x_{i}\right)=\frac{F}{2 \cdot A_{z}}=\frac{F}{2 \cdot a \cdot l}=\frac{F}{h \sqrt{2} \cdot l}= \\
& =\frac{F}{\sqrt{2} \cdot x_{1} \cdot x_{2}} \leq \tau_{d},
\end{aligned}
$$

For allowable tension shear $\tau_{d}$, will apply to: 


$$
\tau_{d} \geq \frac{F}{\sqrt{2} \cdot x_{1} \cdot x_{2}} \tau_{d} \geq \tau\left(x_{i}\right),
$$

Dividing equation (50) to be:

$$
1 \geq \frac{F}{\tau_{d} \cdot \sqrt{2} \cdot x_{1} \cdot x_{2}},
$$

or as a function of the limits being:

$$
F_{g 1}=\frac{F}{\tau_{d} \cdot \sqrt{2}} x_{1}^{-1} \cdot x_{2}^{-1} \leq 1,
$$

Shape of function $F_{g 1}$ and other function of optimization in this form, as will be seen that it is suitable for optimization.

2. Restrictions on the normal stress stretch material of manufacturers, [21,22,24].

The actual tension will be less than the allowable:

$$
\sigma\left(x_{i}\right)=\frac{F}{A}=\frac{F}{t \cdot b} \leq \sigma_{d},
$$

respectively:

$$
\frac{F}{t \cdot b \cdot \sigma_{d}} \leq 1,
$$

given the limitations of the function being:

$$
\begin{aligned}
& F_{g 2}=\frac{F}{t \cdot b \cdot \sigma_{d}}=\frac{F}{x_{3} \cdot x_{4} \cdot \sigma_{d}}= \\
& =\frac{F}{\sigma_{d}} x_{3}{ }^{-1} \cdot x_{4}{ }^{-1} \leq 1,
\end{aligned}
$$

3. Restrictions related to the practical possibility of getting welds

This limit is expressed as, $b \geq h$, as the beam width must be greater than the weld parameter $h$. It follows that:

$$
x_{4} \geq x_{1} 1 \geq \frac{x_{1}}{x_{4}},
$$

Given the limitations of the function being:

$$
F_{g 3}=\frac{x_{1}}{x_{4}} \leq 1 F_{g 3}=x_{1} \cdot x_{4}^{-1} \leq 1,
$$

4. Restrictions on the non-negativity variables $x_{i}$.

This limitation is expressed by the function:

$$
F_{g 4}=x_{i} \geq 0
$$

d) A mathematical model of optimization

According to exposed relations (48), (52), (55), (57), (58) for the observed structural structure, the mathematical model of optimization will be:

$F_{c}=T=$

$\min \left[\left(\frac{T_{11}}{Q_{z}}+T_{3}\right) \cdot x_{1}^{2} \cdot x_{2}+T_{4} \cdot x_{2} \cdot x_{3} \cdot x_{4}+T_{4} \cdot L \cdot x_{3} \cdot x_{4}\right]$,

$$
D\left\{\begin{array}{l}
F_{g 1}=\frac{F}{\tau_{d} \cdot \sqrt{2}} x_{1}^{-1} \cdot x_{2}^{-1} \leq 1 \\
F_{g 2}=\frac{F}{\sigma_{d}} x_{3}^{-1} \cdot x_{4}^{-1} \leq 1 \\
F_{g 3}=x_{1} \cdot x_{4}^{-1} \leq 1 \\
F_{g 4}=x_{i} \geq 0
\end{array},\right.
$$

The function (59), the cost of preparation $T_{p}$ as a constant for the observed relation is not taken into account since they do not affect the mathematical analysis that follows. Once the minimum function of the $F_{c}$, the same value must only add the cost of the preparation, with respect to the relation (40).

By introducing the (constant):

$$
\begin{aligned}
& T_{13}=\frac{T_{11}}{Q_{z}}+T_{3} \\
& F_{a}=\frac{F}{\sqrt{2} \cdot \tau_{d}} F_{b}=\frac{F}{\sigma_{d}},
\end{aligned}
$$

Relation (59) and (60) are simplified:

$$
\begin{array}{r}
F_{c}=T=\min \left[T_{13} \cdot x_{1}{ }^{2} \cdot x_{2}+T_{4} \cdot x_{2} \cdot x_{3} \cdot x_{4}+T_{4 L} \cdot x_{3} \cdot x_{4}\right] \\
F_{g 1}=F_{a} \cdot x_{1}^{-1} \cdot x_{2}^{-1} \leq 1, F_{g 3}=x_{1} \cdot x_{4}^{-1} \leq 1
\end{array}
$$

where in:

$$
x_{1} \geq 0 ; x_{2} \geq 0 ; x_{3} \geq 0 ; x_{4} \geq 0
$$

According to the algorithm in chapter 2.2. for the case that there are limits, the corresponding dual function, considering to (62), will be:

$Q(q)=\left(\frac{T_{13}}{q_{1}}\right)^{q_{1}} \cdot\left(\frac{T_{4}}{q_{2}}\right)^{q_{2}} \cdot\left(\frac{T_{4 L}}{q_{3}}\right)^{q_{3}} \cdot\left(\frac{F_{a}}{q_{4}}\right)^{q_{4}}$

$\cdot\left(\frac{F_{b}}{q_{5}}\right)^{q_{5}} \cdot\left(\frac{1}{q_{6}}\right)^{q_{6}} \cdot q_{4}^{q_{4}} \cdot q_{5}^{q_{5}} \cdot q_{6}^{q_{6}}$,

after the task has a total of six members: $r=6$, and three in the $F_{c}$ and three in the $F_{g}$, since there are three function limitation $(t=1)$ each having a single member.

From the condition of normality (35) and (36) and orthogonal forms a system of five equations with six unknown:

$$
\begin{aligned}
& \text { (I) } q_{1}+q_{2}+q_{3}=1 \\
& \text { (II) } 2 q_{1}-q_{4}+q_{6}=0 \\
& \text { (III) } q_{1}+q_{2}-q_{4}=0 \\
& \text { (IV) } q_{2}+q_{3}-q_{5}=0 \\
& \text { (V) } q_{2}+q_{3}-q_{5}-q_{6}=0,
\end{aligned}
$$


Obviously, I equation is a condition of normality ( $F \mathrm{c}$ function has three members, and therefore appears $\left(q_{1}, q_{2}, q_{3}\right)$, while the other equation (II-V) are orthogonality, in order to variable $x_{1}, x_{2}, x_{3}$ and $x_{4}$.

In this equation (II) is determined by $x_{1}$, the equation (III) by $x_{2}$, the equations (IV) to $x_{3}$, and the equation (V) according to $x_{4}$, taking into account their exponents. Total number of $q_{i}(i=1-6)$ is equal to the number of members of the $F_{c}$ function and the function limitation $(3+1+1+1=6)$.

Equation $\mathrm{V}$ by subtracting equation IV, it follows that:

$$
q_{6}=0 \text {, }
$$

By using the Gaussian algorithm, a simple way to show that all of the unknowns can be expressed in terms of $q_{1}$.

From the second equation it follows that:

$$
q_{4}=2 q_{1} \text {, }
$$

as follows from the III:

$$
q_{2}=q_{1} \text {, }
$$
that:

At the end of the equation I and IV it follows

$$
\begin{aligned}
& q_{3}=1-2 q_{1} \\
& q_{5}=1-q_{1},
\end{aligned}
$$

Rearranging equation (63), it will be simplified:

$Q(q)=\left(\frac{T_{13}}{q_{1}}\right)^{q_{1}} \cdot\left(\frac{T_{4}}{q_{2}}\right)^{q_{2}} \cdot\left(\frac{T_{4 L}}{q_{3}}\right)^{q_{3}} \cdot F_{a}^{q_{4}} \cdot F_{b}^{q_{5}} \cdot 1^{q_{6}}$,

substituting $q_{2}, q_{3}, q_{4}, q_{5}, q_{6}$, and by (65), (66), (67) and (68), equation (69) becomes:

$Q(q)=\left(\frac{T_{13}}{q_{1}}\right)^{q_{1}} \cdot\left(\frac{T_{4}}{q_{1}}\right)^{q_{1}} \cdot\left(\frac{T_{4 L}}{1-2 q_{1}}\right)^{1-2 q_{1}} \cdot F_{a}^{2 q_{1}} \cdot F_{b}^{1-q_{1}}$,

Obviously, the dual function $Q(q)$ is expressed in more than $q_{1}$, which was the goal.

Logarithmic functions (70) will be:

$$
\begin{aligned}
& \ln Q(q)=q_{1} \ln \left(\frac{T_{13}}{q_{1}}\right)+q_{1} \ln \left(\frac{T_{4}}{q_{1}}\right)+\left(1-2 q_{1}\right) . \\
& \cdot \ln \left(\frac{T_{4 L}}{1-2 q_{1}}\right)+2 q_{1} \ln F_{a}+\left(1-q_{1}\right) \ln F_{b},
\end{aligned}
$$

Let $\overrightarrow{q_{0}}=q_{j 0}, j=\overline{1,6}$, the stationary point of the vector in which the $Q(q)_{\max }=Q_{0 \text { max }}$, then the same count is achieved and maximum functions $\ln Q(q)$, according to the (71).

So to calculate the derivative of the function $\ln Q(q)$ the variable $q_{1}$ and equates it to zero:

$$
\frac{d}{d q_{1}}[\ln Q(q)]=0,
$$

Given that this is a complex function, for simplification to (71), we can introduce shifts:

$Q_{1}=q_{1}\left(\ln T_{13}-\ln q_{1}\right)=q_{1} \ln T_{13}-q_{1} \ln q_{1}$

$Q_{2}=q_{1} \cdot \ln \left(\frac{T_{4}}{q_{1}}\right)$

$Q_{3}=\left(1-2 q_{1}\right) \cdot \ln \left(\frac{T_{4 L}}{1-2 q_{1}}\right)=\ln \left(\frac{T_{4 L}}{1-2 q_{1}}\right)-$

$-2 q_{1} \ln \left(\frac{T_{4 L}}{1-2 q_{1}}\right)$

$Q_{4}=2 q_{1} \ln F_{a}$

$Q_{5}=\left(1-q_{1}\right) \cdot \ln F_{b}=\ln F_{b}-q_{1} \ln F_{b}$

With this shift, the function (71) becomes:

$$
\ln Q(q)=Q_{1}+Q_{2}+Q_{3}+Q_{4}+Q_{5} \text {, }
$$

Derivative of (74) will be:

$$
\frac{d[\ln Q(q)]}{d q_{1}}=Q_{1}^{\prime}+Q_{2}^{\prime}+Q_{3}^{\prime}+Q_{4}^{\prime}+Q_{5}^{\prime},
$$

Partial derivative of functions (75) for $q_{1}$ will be to $(73)$ :

$Q_{1}^{\prime}=\ln T_{13}-\left(\ln q_{1}+1\right), Q_{2}^{\prime}=\ln \frac{T_{4}}{q_{1}}-1$

$Q_{3}^{\prime}=\frac{2}{1-2 q_{1}}-2 \cdot \ln T_{4 L}+2 \cdot \ln \left(1-2 q_{1}\right)-\frac{4 \cdot q_{1}}{1-2 q_{1}}$

$Q_{4}^{\prime}=2 \cdot \ln F_{a}, Q_{5}^{\prime}=-\ln F_{b}$

Substituting extracts partial functions (76) in (75) will be after the arranging, according to (72):

$$
\begin{aligned}
& \frac{2}{1-2 q_{1}}-\frac{4 q_{1}}{1-2 q_{1}}+\ln \left(\frac{T_{4}}{q_{1}}\right)+2 \cdot \ln \left(1-2 q_{1}\right)+ \\
& +\ln \left(\frac{T_{13}}{q_{1}}\right)-2-2 \ln T_{4 L}+\ln \frac{F_{a}^{2}}{F_{b}}=0
\end{aligned}
$$

Equation (77), after some mathematical operations can be summarized as:

$$
\ln \left(\frac{1-2 q_{1}}{q_{1}}\right)^{2}+\ln \left(\frac{T_{13} \cdot T_{4 L} \cdot F_{a}^{2}}{T_{4}{ }^{2} \cdot F_{b}}\right)=0,
$$

It follows that:

$$
\left(\frac{1-2 q_{1}}{q_{1}}\right)^{2}=\frac{T_{4 L}^{2} \cdot F_{b}}{T_{13} \cdot F_{a}^{2} \cdot T_{4}},
$$

and finally, solving to $q_{1} \equiv q_{0}$ :

$$
q_{10}=\frac{1}{2+\frac{T_{4 L}}{F_{a}} \cdot \sqrt{\frac{F_{b}}{T_{13} \cdot T_{4}}}},
$$

Taking into account (65), (66), (67), (68) and (80) it follows that: 


$$
\begin{aligned}
& q_{20}=q_{10} \\
& q_{30}=1-2 \cdot q_{10}=1-\frac{2}{2+\frac{T_{4 L}}{F_{a}} \cdot \sqrt{\frac{F_{b}}{T_{13} \cdot T_{4}}}} \\
& q_{40}=2 \cdot q_{10}=\frac{2}{2+\frac{T_{4 L}}{F_{a}} \cdot \sqrt{\frac{F_{b}}{T_{13} \cdot T_{4}}}}, \\
& q_{50}=1-q_{10}=1-\frac{1}{2+\frac{T_{4 L}}{F_{a}} \cdot \sqrt{\frac{F_{b}}{T_{13} \cdot T_{4}}}}
\end{aligned}
$$

$q_{60}=0$

Accordingly, an optimal dual vector has a component:

$$
\vec{q}_{0}=\left(q_{10} ; q_{20} ; q_{30} ; q_{40} ; q_{50} ; q_{60}\right),
$$

By setting the calculated optimum dual component vectors $\vec{q}_{0}$ (82) corresponding to a maximum of the dual function of (25)

$$
\begin{aligned}
& Q(q)_{\max }=\max Q(q)=Q_{0}= \\
& =Q\left(q_{10} ; q_{20} ; q_{30} ; q_{40} ; q_{50} ; q_{60}\right),
\end{aligned}
$$

receives the value of the minimum function optimization, ie.:

$$
F_{c 0}=\min F_{c}=\max Q(q)=Q\left(q_{0}\right)=Q_{0},
$$

Based on $F_{c 0}$, calculated from equation (62) to (37) components of the optimal vector of the system:

$$
\begin{aligned}
& \text { (I) } T_{13} \cdot x_{10}^{2} \cdot x_{20}=Q_{0} \cdot q_{10} \\
& \text { (II) } T_{4} \cdot x_{20} \cdot x_{30} \cdot x_{40}=Q_{0} \cdot q_{20} \\
& \text { (III) } T_{4 L} \cdot x_{30} \cdot x_{40}=Q_{0} \cdot q_{30} \\
& \text { (IV) } F_{a} \cdot x_{10}^{-1} \cdot x_{20}^{-1}=\frac{q_{40}}{\lambda_{40}}=\frac{\lambda_{40}}{\lambda_{40}}=1 \\
& \text { (V) } F_{b} \cdot x_{30}^{-1} \cdot x_{40}^{-1}=\frac{q_{50}}{\lambda_{50}}=\frac{\lambda_{50}}{\lambda_{50}}=1 \\
& \text { (VI) } x_{10} \cdot x_{40}^{-1}=\frac{q_{60}}{\lambda_{60}}=\frac{\lambda_{60}}{\lambda_{60}}=1
\end{aligned}
$$

From I and IV of the equation it follows that:

$$
x_{10}=\frac{Q_{0} \cdot q_{10}}{T_{13} \cdot F_{a}},
$$

$\mathrm{VI}$ according to the equation it follows that:

$$
x_{40}=x_{10},
$$

From equation IV will be:

$$
x_{20}=\frac{F_{a}}{x_{10}},
$$

Also, from the equation $\mathrm{V}$ will be:

$$
x_{30}=\frac{F_{b}}{x_{40}}=\frac{F_{b}}{x_{10}},
$$

The equations of system (II), (III), (VI), which at present are not used, can be used to control the results obtained with respect to all of the system equation, must be satisfied.

For example, the observed arc welding beam bracket, which are made of carbon structural steel $(0.25 \% \mathrm{C})$, calculated constants:

- The capacity of the welding $Q_{z}=0,05 \frac{\mathrm{cm}^{3}}{\mathrm{~s}}$

- The price of basic material $T_{4}=1,4 \frac{\mathrm{CENT}}{\mathrm{cm}^{3}}$

- The price of electrode material $T_{3}=5,7 \frac{\mathrm{CENT}}{\mathrm{Cm}^{3}}$

- The cost of welding device $T_{1}=0,65 \frac{\text { CENT }}{s}$

Allowable stress of the base material tensile $\sigma_{d}=10000 \frac{\mathrm{N}}{\mathrm{cm}^{2}}$

Allowable stress of the base metal shear $\tau_{d}=5000 \frac{\mathrm{N}}{\mathrm{cm}^{2}}$

- Maximum power load beam $F=20000 \mathrm{~N}$

- Free length of the beam $L=20 \mathrm{~cm}$

Preparation costs $T_{p}=73,9$ CENT

Constant value to $(61)$ will be:

$$
\begin{aligned}
& T_{13}=\frac{T_{11}}{Q_{z}}+T_{3}=\frac{0,75}{0,05}+6,5=18,7 \frac{C E N T}{\mathrm{~cm}^{3}} \\
& F_{a}=\frac{F}{\sqrt{2} \cdot \tau_{d}}=\frac{20000}{\sqrt{2} \cdot 5000}=2,828 \mathrm{~cm}^{2} \\
& F_{b}=\frac{F}{\sigma_{d}}=\frac{20000}{10000}=2 \mathrm{~cm}^{2} \frac{C E N T}{\mathrm{~cm}^{2}}
\end{aligned}
$$

The components of the dual optimum vector to be (80), or according to (81):

$$
\begin{aligned}
q_{10}=\frac{1}{2+\frac{T_{4 L}}{F_{a}} \cdot \sqrt{\frac{F_{b}}{T_{13} \cdot T_{4}}}}=\frac{1}{2+\frac{27,8}{2,828} \cdot \sqrt{\frac{2}{18,7 \cdot 1,4}}}=0,2115 \\
q_{20}=q_{10}=0,2115 \\
q_{30}=1-2 \cdot q_{10}=1-2 \cdot 0,2115=0,577 \\
q_{40}=2 \cdot q_{10}=2 \cdot 0,2115=0,423 \\
q_{50}=1-q_{10}=1-0,2115=0,7885 \\
q_{60}=0
\end{aligned}
$$

The optimum dual vector of $(X)$ will be: 
$\vec{q}_{0}=\left(q_{10} ; q_{20} ; q_{30} ; q_{40} ; q_{50} ; q_{60}\right)=$

$(0,2115 ; 0,2115 ; 0,577 ; 0,423 ; 0,7885 ; 0)$

The optimal values of the dual function $Q_{0}$ to (69) will be:

$$
\begin{aligned}
& Q\left(q_{0}\right)=\left(\frac{T_{13}}{q_{1}}\right)^{q_{10}} \cdot\left(\frac{T_{4}}{q_{2}}\right)^{q_{20}} \cdot\left(\frac{T_{4 L}}{q_{3}}\right)^{q_{30}} \\
& \cdot F_{a}^{q_{40}} \cdot F_{b}^{q_{50}} \cdot 1^{q_{60}}
\end{aligned}
$$

Substituting the values (91) to (92) shall be final:

$Q\left(q_{0}\right)=\left(\frac{18,7}{0,2115}\right)^{0,2115} \cdot\left(\frac{1,4}{0,2115}\right)^{0,2115}$

$\cdot\left(\frac{27,8}{0,577}\right)^{0,577} \cdot 2,828^{0,423} \cdot 2^{0,7885}$

$Q\left(q_{0}\right)=96,4$

where the optimal value of the dual function to function optimization:

$$
F_{c 0}=Q_{0}=Q\left(q_{0}\right)=96,4 \text { CENT, }
$$

On the basis of the value (86), (87) from (88), (89) are determined by the desired optimum vector $x_{0}$ :

$$
\begin{aligned}
& x_{10}=\frac{Q_{0} \cdot q_{10}}{T_{13} \cdot F_{a}}=\frac{96,4 \cdot 0,2115}{18,7 \cdot 2,828}=0,386 \\
& x_{40}=x_{10}=0,386 \mathrm{~cm} \\
& x_{20}=\frac{F_{a}}{x_{10}}=\frac{2,828}{0,386}=7,326 \mathrm{~cm} \\
& x_{30}=\frac{F_{b}}{x_{10}}=\frac{2}{0,386}=5,181 \\
& \mathrm{~cm}
\end{aligned}
$$

Control of the results can be performed according to the equations II, III and $\mathrm{VI}$, of system (85), considering that the same are not used.

Now is the optimal primary vector completely determined:

$$
\vec{q}_{0}=\left(x_{10} ; x_{20} ; x_{30} ; x_{40}\right)=(0,386 ; 7,367 ; 5,181 ; 0,386) \text {, }
$$

When an optimal vector (96), an optimum is achieved $F_{c 0}=\min F_{c}$ according to (62):

$$
\begin{aligned}
& F_{c 0}=T_{13} \cdot x_{10}{ }^{2} \cdot x_{20}+T_{4} \cdot x_{20} \cdot x_{30} \cdot x_{40}+ \\
& +T_{4 L} \cdot x_{30} \cdot x_{40},
\end{aligned}
$$

Substituting (95) into (97) will be: $F_{c}=18,7 \cdot 0,386^{2} \cdot 7,326+1,4 \cdot 7,326 \cdot 5,181 \cdot 0,386$ $+27,8 \cdot 5,181 \cdot 0,386=96,4 C E N T$,

As might be expected, given (93).

In calculation, minimal error ocurred because of rounding of numbers (four digits).
From the above follows that the optimal values of the dimensions of the welded joint observed:

$$
\begin{aligned}
& h_{0}=x_{10}=3,86 \mathrm{~mm}, I_{0}=x_{20}=73,26 \mathrm{~mm}, \\
& t_{0}=x_{30}=51,81 \mathrm{~mm}, b_{0}=x_{40}=3,86 \mathrm{~mm} .
\end{aligned}
$$

One can easily show that all the boundary conditions (60) are fully met.

\subsection{A more complex example}

As a more complex problem let's take the same example of the picture 4 , with the difference that we will introduce two new constraints:

1. In view of the specific construction reasons there is a limit of geometric measure

$$
t \geq b \text {, }
$$

2. Restrictions pertaining to minimum width dimension $h_{1 \min }=x_{1 \min }$, below show that it is not possible to have technological realization of cheating:

$$
h>x_{1 \text { min }} \quad x_{1 \text { min }}=d,
$$

For $x 1 \mathrm{~min}$, a constant value is introduced, which may relate, for example to the minimum diameter of the applied welding electrodes, [24, 25].

Accordingly function optimization (goal) will be to (48):

$$
F_{c}=T_{13} \cdot h^{2} \cdot l+T_{4} \cdot l \cdot t \cdot b+T_{4} \cdot l \cdot t \cdot b,
$$

The first three functions to limit (62), will also be as in the first example:

$$
\begin{aligned}
& F_{g 1}=F_{a} \cdot x_{1}^{-1} \cdot x_{2}^{-1} \leq 1 \\
& F_{g 2}=F_{b} \cdot x_{3}^{-1} \cdot x_{4}^{-1} \leq 1, \\
& F_{g 3}=x_{1} \cdot x_{4}^{-1} \leq 1
\end{aligned}
$$

Due to (99) and (100), the following two new constraints will be:

$$
F_{g 5}=x_{4} \cdot x_{3}^{-1} \leq 1 \quad F_{g 4}=d \cdot x_{1}^{-1} \leq 1,
$$

Obviously, with this, we have maintained the earlier marks geometric size $x_{1}=h \quad x_{2}=l \quad x_{3}=t \quad x_{4}=b$.

All restrictions on the functions here have only one member, and according to chapter 2.2.

$d_{1}=q_{4}, d_{2}=q_{5}, d_{3}=q_{6}, d_{4}=q_{7}, d_{5}=q_{8}$

For this case, an appropriate dual function, as the increased number of functions of limitation, will be more complex:

$Q(q)=\left(\frac{T_{13}}{q_{1}}\right)^{q_{1}} \cdot\left(\frac{T_{4}}{q_{2}}\right)^{q_{2}} \cdot\left(\frac{T_{4 L}}{q_{3}}\right)^{q_{3}} \cdot\left(\frac{F_{a}}{q_{4}}\right)^{q_{4}} \cdot\left(\frac{F_{b}}{q_{5}}\right)^{q_{5}}$. $\cdot\left(\frac{1}{q_{6}}\right)^{q_{6}} \cdot\left(\frac{1}{q_{7}}\right)^{q_{7}} \cdot\left(\frac{1}{q_{8}}\right)^{q_{8}} \cdot q_{4}^{q_{4}} \cdot q_{5}^{q_{5}} \cdot q_{6}^{q_{6}} \cdot q_{7}^{q_{7}} \cdot q_{8}^{q_{8}}$ 
From the conditions of normality and orthogonality $(20,21)$, we obtain the system of equations for determining the optimal dual vectors:

$$
\begin{aligned}
& q_{1}+q_{2}+q_{3}=1 \\
& 2 q_{1}-q_{4}+q_{6}-q_{7}=0 \\
& q_{1}+q_{2}-q_{4}=0 \\
& q_{2}+q_{3}-q_{5}-q_{8}=0 \\
& q_{2}+q_{3}-q_{5}-q_{6}+q_{8}=0
\end{aligned}
$$

Apparently solving the system by (105) cannot act like in the first example, because it is obtained by a system of five linear equations with eight unknowns.

Size and parameters in the equation (104) will be in this example:

$$
\begin{aligned}
& T_{13}=\frac{T_{11}}{Q_{z}}+T_{3}=\frac{0,75}{0,05}+6,5=18,7 \frac{\text { CENT }}{\mathrm{cm}^{3}} \\
& T_{4}=1,4 \frac{C E N T}{\mathrm{~cm}^{3}} \\
& T_{4 L}=T_{4} \cdot L=1,6 \cdot 20=27,8 \frac{\mathrm{CENT}}{\mathrm{cm}^{2}} \\
& F_{a}=\frac{F}{\sqrt{2} \cdot \tau_{d}}=\frac{20000}{\sqrt{2} \cdot 5000}=2,84 \mathrm{~cm}^{2} \\
& F_{b}=\frac{F}{\sigma_{d}}=\frac{20000}{10000}=2 \quad \mathrm{~cm}^{2} d=0,3 \mathrm{~cm}^{2}
\end{aligned}
$$

There is the adopted size $d=3 \mathrm{~mm}$, in view of the minimum diameter of the electrode for carrying out the welding operation.

\subsubsection{Analysis of the level of complexity}

For the simple case when the number of equations (26) is equal to the number of unknown values (dual variables) of the system is obtained unambiguously (a) solution $\vec{q}_{0}=\left(q_{j 0}\right)$. It is possible, however, and in the other (more complex) case, with the system (25a), (26), that the number of unknown size qj is greater than the number of available equations. Then we cannot talk about the optimal vector $\vec{q}_{0}$ with regard to $\dot{q}$, because $\dot{q}$ is multifacted, and it has many infinitely more respective solutions and the optimal solution $\vec{q}_{0}$ which achieve optimum $Q_{0}$, obtained by maximizing the dual function $Q(q)$, ie. solving the optimal task (dual task optimization) defined system (25a). When this is used in some of the analytical methods, for example, non-linear programming method of $[13,15,7,12]$. Here is the procedure of optimization easier, because all constraints are of linear shape.

Other (more complex) case is associated with the degree of complexity, which is defined by the equation:

$$
s=r-\left(k^{\prime}+1\right),
$$

where $r$ - number of minimal positive polynomials and $k$ '-size related to the number of independent variables in the above polynomial whose reality defines the rank of a matrix built by the exponents bij in the polynomial (9), [16,25,26]. For the case that $s=0$, it does not solve the task of optimizing the dual function $Q$ (q) but the $\vec{q}_{0}$ is determined unambiguously by the system (26).

For $s=1$ (the first example), as shown by the optimum solution $\vec{q}_{0}$ is obtained by maximizing the dual function $Q(q)$.

Considering the above, the exponent for matrices another example, the system is determined by the equation (105) wherein the first equation of the system is not taken into account:

$$
M_{e}=\left\|\begin{array}{cccccccc}
2 & 0 & 0 & -1 & 0 & 1 & -1 & 0 \\
1 & 1 & 0 & 0 & -1 & 0 & 0 & 0 \\
0 & 1 & 1 & 0 & -1 & 0 & 0 & -1 \\
0 & 1 & 1 & 0 & -1 & -1 & 0 & 1
\end{array}\right\|
$$

Rank of the matrix (107), using matrices and using matrix properties (operations with matrices) will be:

$$
\begin{aligned}
& \operatorname{RangM}_{e}=\left\|\begin{array}{llllllcc}
0 & 0 & 0 & 0 & 0 & 0 & 1 & 0 \\
0 & 0 & 0 & 0 & 1 & 0 & 0 & 0 \\
0 & 0 & 0 & 0 & 0 & 0 & 0 & -1 \\
0 & 0 & 0 & 0 & 0 & 1 & 0 & 0
\end{array}\right\|= \\
& \left\|\begin{array}{llllllll}
1 & 0 & 0 & 0 & 0 & 0 & 0 & 0 \\
0 & 1 & 0 & 0 & 0 & 0 & 0 & 0 \\
0 & 0 & 1 & 0 & 0 & 0 & 0 & 0 \\
0 & 0 & 0 & 1 & 0 & 0 & 0 & 0
\end{array}\right\|=4
\end{aligned}
$$

The degree of complexity is defined as

$$
s=r-\left(k^{\prime}+1\right)=8-(4+1)=3,
$$

Here $r$ is the number of minimizing polynomials, $k$-size related to the number of independent variables in a positive polynomial (9) whose value defines the rank of the matrix formed by the exponents in the polynomial (9). Given that $s>0$, the optimal dual vector $\vec{q}_{0}$ can be obtained from the equation system (9), since the number of these equations is less than the number of unknown values $q_{j} \cdot \vec{q}_{0}$. Then $\vec{q}_{0}$ is obtained by maximizing the dual function $Q(q)$ using one of the analytical methods, for example, non-linear programming method [13-15,12].

\subsubsection{Solving problems by using nonlinear programming}

Substituting known parameters to a function (104), using an appropriate program by using met- 
hod of nonlinear programming, to obtain the optimal dual component vectors:

$$
\begin{array}{llll}
q_{10} & =0,212 \quad q_{20}=0,212 \quad q_{30}=0,576 \quad q_{40}=0,424 \\
q_{50} & =0,788 \quad q_{60}=0 \quad q_{70}=0 \quad q_{80}=0
\end{array}
$$

That is:

$$
\vec{q}_{0}=(0,212 ; 0,212 ; 0,576 ; 0,424 ; 0,788 ; 0 ; 0 ; 0)
$$

These values are obtained considering to $Q(q)_{\max }$.

By entering the calculated values of the components $\vec{q}_{0}(\mathrm{X})$, the peak corresponding dual function (104) will be:

$$
\begin{aligned}
& Q(q)_{\max }=\max Q(q)=Q_{0}= \\
& =Q\left(q_{10} ; q_{20} ; q_{30} ; q_{40} ; q_{50} ; q_{60} ; q_{70} ; q_{80}\right)=96,6 \text { CENT }
\end{aligned}
$$

Thus the minimum value of function optimization will be:

$$
F_{c 0}=\min F_{c}=\max Q(q)=Q\left(q_{0}\right)=Q_{0}=96,6 C E N T
$$

Basis $F_{c 0}=96,6$ calculated from equation (97) components of the optimal vector according to equation (37):

$$
\begin{aligned}
& T_{13} \cdot x_{10}^{2} \cdot x_{20}=Q_{0} \cdot q_{10} \\
& T_{4} \cdot x_{20} \cdot x_{30} \cdot x_{40}=Q_{0} \cdot q_{20} \\
& T_{42} \cdot x_{30} \cdot x_{40}=Q_{0} \cdot q_{30} \\
& F_{a} \cdot x_{10}^{-1} \cdot x_{20}^{-1}=\frac{q_{40}}{\lambda_{40}}=\frac{q_{40}}{q_{40}}=1 \\
& F_{b} \cdot x_{30}^{-1} \cdot x_{40}^{-1}=\frac{q_{50}}{\lambda_{50}}=\frac{q_{50}}{q_{50}}=1 \\
& x_{10} \cdot x_{40}^{-1}=\frac{q_{60}}{\lambda_{60}}=\frac{q_{60}}{q_{60}}=1 \\
& d \cdot x_{10}^{-1}=\frac{q_{70}}{\lambda_{40}}=\frac{q_{70}}{q_{70}}=1 \\
& x_{40} \cdot x_{30}^{-1}=\frac{q_{80}}{\lambda_{50}}=\frac{q_{80}}{q_{80}}=1
\end{aligned}
$$

The resulting system of linear equations (110) is solved relatively easily.

From second and third equations of the system (110) that the

$$
T_{4} \cdot x_{20} \cdot \frac{Q_{0} \cdot q_{30}}{T_{42}}=Q_{0} \cdot q_{20}
$$

From here it is

$$
x_{20}=\frac{q_{20} \cdot T_{41}}{T_{4} \cdot q_{30}}=\frac{0,212 \cdot 27,8}{1,4 \cdot 0,576}=7,361
$$

Now, from the first equation of the system (110) that follows:

$$
x_{10}=\sqrt{\frac{Q_{0} \cdot q_{10}}{T_{13} \cdot x_{20}}}=\sqrt{\frac{96,6 \cdot 0,212}{18,7 \cdot 7,361}}=0,3858
$$

The fourth equation of system can be used to check the results: $F_{a}=x_{10} \cdot x_{20}$

Then from third equation we have:

$$
x_{30}=\sqrt{\frac{Q_{0} \cdot q_{30}}{T_{4 L}}}=\sqrt{\frac{96,6 \cdot 0,576}{27,8}}=x_{40}=1,41
$$

From this equation it follows that $x_{30}=x_{40}$

The second equation of system may also be used to check the results, given that sizes are known in the equations. The same applies to the fifth equation system,

$$
F_{b}=x_{30} \cdot x_{40}=2
$$

Thus the optimal size for a more complicated case of optimization will be:

$x_{10}=h_{0}=3,858 \mathrm{~mm}, x_{20}=I_{0}=73,61 \mathrm{~mm}$,

$x_{30}=t_{0}=14,10 \mathrm{~mm}, x_{40}=b_{0}=14,10 \mathrm{~mm}$

\section{CONCLUSION}

A method of programming is displayed in a geometrical operation, used principally in the production of various technologies. It is shown that the method under certain circumstances, is used in the field of design. Special methods efficiency is achieved when the associated technology and construction resistance are shown in the examples.

Many of the functions encountered in practice, certain mathematical transformations, can be reduced to positive polynomials and applied to the present model.

The model presented in the paper through the course of the algorithm can be considered as a more general and can be applied in many areas of design where it can be taken into account within technologies, while it is possible to apply various technical and economic criteria in optimization. All amounts to structural and technological solutions in the process of establishing the optimal project to determine the best possible. Limit function can be different both in number and shape.

Application of geometric programming is possible with different functions of optimization and constraints as linear and nonlinear. Complex problems are present in this system of linear equations that are relatively easy to solve, which is an advantage compared to other methods (for example, simplex method, and a gradient). The solution is always obtained directly without optimal search area. Special attention when applying the method of geometric programming should be processed when the limit function contains more than one member. Then the appropriate member of the effectiveness of a dual function also includes more members.

In most problems, in the end here occur more equations than necessary. This allows you to monitor and control the results with respect to all equations of the system that must be met. Also, control can be exercised towards equality $\operatorname{minF}_{c}=$ $\max$. 
Like any method of optimization and geometric programming method has its drawbacks.

The method can not be applied to cases where the optimization function and constraints are positive polynomials (when it appears in the polynomial minus sign). It should be noted that the technical practices in such cases are generally rare.

Finally, it should be pointed out that modern optimization methods for efficient implementation require multidisciplinary knowledge required of different fields: technology, design,construction, economics, mathematical analysis, mathematical programming. These are probably the main reasons why we are in technical practice insufficiently engaged it cannot as well be justified.

\section{REFERENCES}

[1] H.J.Jacobs, E. Jacob (1988) Spanungsoptimierung, Verfahrensgestaltung durch tehnologiesche Optimiering in drt Spanunstechnik, Veb Verlag Technik, Berlin.

[2] I.Ham, R.Faria-Gonzales (1971) Production Optimization Method using a Digital Computer, Oxford.

[3] Z.Majcen (1988) Troškovi u teoriji i praksi, Informator, Zagreb.

[4] B.Draženović, E.Humo (1982) Problemi upravljanjem složenim sistemima, Informator, Zagreb.

[5] D.J.Wilde (1988) Globally optional design, J.Wiley, New York.

[6] G.V.Reklaitis (1993) Ravidran A. Engeneering optimization, Methods and applications, J.Wiley, New York.

[7] R.Gabasov, F.M.Kirilov (1991) Metodi optimizacije, BGU, MInsk.

[8] J.Petrić, L.Šarenac (1984) Operaciona istraživanja I i II, Zbirka rešenih zadataka, Naučna knjiga, Beograd.

[9] A.M.Cirlin (1996) Optimalnoe upravlenie tehnologičestimi processami, Energoatomizdat, Moskva.
[10] H.Opitz (1980) Moderne produktiontechnik, Stand und tendenzen, 3. Auflage, Verlag W. Girardek, Essen.

[11] M.E.Zohadi (1994) Statistical Analysis, estimation and optimization of surface finish in the grinding process, Development of Production System, Taylor-Francis LTD, London.

[12] J.Petrić (1993) Operaciona istraživanja, Knjiga I i II, Savremena administracija, Beograd.

[13] J.Petrić, S. Zlobec (1983) Nelinearno programiranje, Naučna knjiga, Beograd.

[14] R.J.Duttin, E.L.Peterson (1987) Geometricprogramming-Theory and application, J.Willey, New York.

[15] N.J.Kuznecov (1990) Matematičeskoe programirovanije, Visšaja škola, Moskva.

[16] Akulič, I. L. (1996) Matimatičsekoe programirovanije v primerah i zadačah, Visšaja škola, Moskva,

[17] F.S.Novak, J.B.Arsov (1980) Optimizacija processov tehnologii metallov, Mašinostroenie-Tehnika, Moskva-Sofija.

[18] S.Berberović, B.Stavrić (1998) Teorija i metodologija troškova, Savremena administracija, Beograd.

[19] V.Kolarić (1985) Teorija dinamike troškova, Rad, Beograd.

[20] D.Zelenović (1983) Proizvodni sistemi, Naučna knjiga, Beograd.

[21] M.Milosavljević, M.Radojković (1995) Čelične konstrukcije, Građevinska knjiga, Beograd.

[22] C.Jovanović (1987) Zavarene konstrukcije, Građevinske konstrukcije, Građevinska knjiga, Beograd.

[23] R.Green (1985) Weld Design, Prentice-Hall, New York,

[24] C.Hase, W.Reitze (1992) Lehrbuch des Lichtbogenschwei-ssens, C.Verlag W.Girardet, Essen,.

[25] D.S.Mitriković, D.Mihailović (1998) Linearna algebra, Građevinska knjiga, Beograd.

[26] S.Kurepa (1990) Matematička analiza I i II, Tehnička knjiga, Zagreb.

\section{IZVOD}

\section{OPTIMIZACIJA DIMENZIJA OPTEREĆENOG ZAVARENOG SKLOPA METODOM GEOMETRIJSKOG PROGRAMIRANJA}

U radu je na primeru jednog karakterističnog opterećenog zavarenog sklopa izvršena optimizacija njegovih dimenzija sa aspekta troškova zavarivanja. Pri ovome, postavljen je matematički model optimizacije sa finkcijama ograničenja koje pri projektovanju moraju uzeti u obzir tehnolog i konstruktor. Za rešavanje postavljenog problema, predložen je metod geometrijskog programiranja koji je detaljno razrađen u radu u obliku algoritma pogodnog za primenu. Na taj način optimizacioni ili primarni zadatak, sveo se na dualni zadatak preko odgovarajuće funkcije, koji se znatno lakše rešava.

Metod je ilustrovan na jednom računskom praktičnom primeru sa različitim brojem funkcija ograničenja. Pokazano je da se za slučaj manjeg stepena složenosti do rešenja može doći maksimizacijom odgovarajuće dualne funkcije primenom matematičke analize. Za slučaj većeg stepena složenosti, neophodna je primena neke od metoda nelinearnog programiranja. U ovom slučaju rešenje problema je pojednostavljeno zbog svođenja linerane jednačine.

Ključne riječi: zavarene strukture po abecednom redosledu, matematički model optimizacije, funkcija troškova, karakteristična ograničenja, geometrijsko programiranje, pozitivni polinomi, dvostruka funkcija. Naucni rad

Rad primljen: 23. 03. 2015.

Rad prihvacen: 11. 05. 2015.

Rad je dostupan na sajtu: www.idk.org.rs/casopis 